\title{
Indomethacin induces apoptosis in the EC109 esophageal cancer cell line by releasing second mitochondria-derived activator of caspase and activating caspase-3
}

\author{
SIDA QIN ${ }^{1}$, CHONGWEN XU $^{1}$, SHUO LI $^{1}$, CHENGCHENG YANG $^{2}$, XIN SUN $^{1}$, \\ XIFANG WANG $^{1}$, SHOU-CHING TANG ${ }^{3,4}$ and HONG REN ${ }^{1}$ \\ Departments of ${ }^{1}$ Thoracic Surgery and ${ }^{2}$ Oncology, First Affiliated Hospital, School of Medicine, \\ Xi'an Jiaotong University, Xi'an, Shaanxi 710061, P.R. China; ${ }^{3}$ Department of Hematology and Oncology, \\ Georgia Regents University Cancer Center, Augusta, GA 30912, USA; \\ ${ }^{4}$ Tianjin Medical University Cancer Institute and Hospital, Tianjin 300060, P.R. China
}

Received April 17, 2014; Accepted December 19, 2014

DOI: $10.3892 / \mathrm{mmr} .2015 .3331$

\begin{abstract}
The use of non-steroidal anti-inflammatory drugs (NSAIDs) has been associated with a reduced risk of various types of cancer, including esophageal cancer. However, the mechanisms underlying the antineoplastic effects of NSAIDs in esophageal cancer remain to be elucidated. In the present study, a significant inhibition in cell viability was observed in the EC109 cells following treatment with different concentrations of indomethacin, and these effects occurred in a dose- and time-dependent manner. This inhibition was due to the release of second mitochondria-derived activator of caspase (Smac) into the cytosol and the activation of caspase-3. Subsequently, flow cytometry was performed to investigate indomethacin-induced apoptosis following the overexpression or knockdown of Smac, and western blot analysis was performed to determine the expression of Smac and the activation of caspase-3. Overexpression of Smac was promoted apoptosis, while downregulation of Smac significantly inhibited apoptosis. Western blot analysis demonstrated that indomethacin induced apoptosis through releasing Smac into the cytosol and activating caspase-3. These results indicated that Smac is essential for the apoptosis induced by indomethacin in esophageal cancer cells.
\end{abstract}

Correspondence to: Professor Hong Ren, Department of Thoracic Surgery, First Affiliated Hospital, School of Medicine, Xi'an Jiaotong University, 227 Yanta West Road, Xi'an, Shaanxi 710061, P.R. China E-mail: renhongs2000@gmail.com

Professor Shou-Ching Tang, Department of Hematology and Oncology, Georgia Regents University Cancer Center, 1411 Laney Walker Blvd, Augusta, GA 30912, USA

E-mail: stang@gru.edu

Key words: esophageal cancer, non-steroidal anti-inflammatory drugs, Smac, indomethacin, apoptosis

\section{Introduction}

The second mitochondria-derived activator of caspase (Smac) protein is a novel protein, which is involved in the mitochondrial regulation of apoptosis $(1,2)$. It has been observed that the expression of Smac is reduced in various types of malignant tissue compared with their normal tissue counterparts, which suggests that it may function as a novel tumor suppressor protein $(3,4)$. Several previous studies have demonstrated that Smac promotes apoptosis by binding to the inhibitor of apoptosis proteins (IAPs), leading to release of caspases from the IAPs and to the activation of the caspase cascade (5-7).

Previous epidemiological, preclinical and clinical studies have suggested that indomethacin and other non-steroidal anti-inflammatory drugs (NSAIDs) may possess anticancer activities (8). A study by Kohli et al (9) observed that indomethacin promoted apoptosis in the HCT116 colon cancer cell line and this effect was attenuated by knockout of the Smac gene, which suggested that Smac is important in the apoptosis induced by NSAIDs. In addition, a study by Bank et al (10) demonstrated that Smac sensitizes NSAID-induced apoptosis by promoting the activation of caspase- 3 and the release of cytochrome $c$. This result further elucidated the mechanism by which Smac enhances NSAID-induced apoptosis in colon carcinoma cells.

Esophageal cancer is a common type of human upper gastrointestinal carcinoma and, in 2008, a total of 400,000 individuals succumbed to mortality, worldwide and 480,000 new cases were diagnosed (11). Previous clinical trials have indicated that NSAIDs are able to significantly reduce the risk of esophageal cancer $(12,13)$. The effects of indomethacin on the growth, apoptosis and expression of Smac in esophageal cancer cells remain to be fully elucidated. In the present study, indomethacin-mediated apoptosis was investigated in EC109 esophageal cancer cells by overexpression or knockdown of Smac, to examine the mechanism by which NSAIDs control the growth and survival of esophageal carcinoma cells. 


\section{Materials and methods}

Cell culture and cell transfection. The human EC109 esophageal cancer cells were obtained from the American Type Culture Collection (Manassas, VA, USA) and maintained at $37^{\circ} \mathrm{C}$ and $5 \% \mathrm{CO}_{2}$ in RPMI 1640 medium (HyClone Laboratories, Inc., Logan, UT, USA) supplemented with $10 \%$ fetal bovine serum (GE Healthcare Life Sciences, Logan, UT, USA), $100 \mathrm{U} / \mathrm{ml}$ penicillin and $100 \mathrm{~g} / \mathrm{ml}$ streptomycin (Sigma-Aldrich, St. Louis, MO, USA). The EC109 cells were transfected with Lipofectamine ${ }^{\mathrm{TM}} 2000$ (Invitrogen Life Technologies, Carlsbad, CA, USA), according to the manufacturer's instructions, during the logarithmic growth phase. Subsequent experiments were performed 48-h after transfection. The pcDNA3.1-Smac vector was constructed in our previous work (14). In brief, Smac was amplified from the mRNA of human testis tissue by reverse transcription polymerase chain reaction (RT and PCR kits, Takara Bio, Inc., Dalian, China; S1000 Thermal cyclers, Bio-Rad Laboratories, Inc., Hercules, CA, USA) using the following primers: Forward 5'-CGGGATCCCACAATGGCGGCTCTGA-3' and reverse 5'-CCCAAGCTTGGCCCTCAATCCTCACGC-3'. Then, it was digested by BamHI and HindIII (Takara Bio, Inc.) and inserted into pcDNA3.1 (Invitrogen Life Technologies) by T4 DNA ligase (Invitrogen Life Technologies). The small interference RNA (siRNA) and the control fragment for Smac RNAi were designed and synthesized by Shanghai GenePharma Co., Ltd. (Shanghai, China).

MTT assay. Cell viability was assessed using a methyl-thiazol tetrazolium (MTT) assay. Exponentially growing EC109 cells were seeded into 96-well plates at a density of $1 \times 10^{3}$ cells/well and incubated for $24 \mathrm{~h}$ at $37^{\circ} \mathrm{C}$. Different concentrations (0, 50, 100, 200, 400 and $800 \mu \mathrm{M})$ of indomethacin (Sigma-Aldrich) were then added to the wells and incubated at $37^{\circ} \mathrm{C}$ for 24,48 and $72 \mathrm{~h}$. A total of $10 \mu 1$ sterile MTT ( $5 \mathrm{mg} / \mathrm{ml}$; Sigma-Aldrich) was added to each well. Following a further incubation at $37^{\circ} \mathrm{C}$ for $4 \mathrm{~h}$, the reaction was stopped by the addition of $150 \mu \mathrm{l}$ dimethyl sulfoxide. After $10 \mathrm{~min}$, the formazan production was determined by measurement of the spectrometric absorbance at a wavelength of $490 \mathrm{~nm}$ using an enzyme immunoassay analyzer (xMark ${ }^{\mathrm{TM}}$ Microplate Absorbance spectrophotometer; Bio-Rad Laboratories, Inc.).

Flow cytometryassay. The cells were plated into 24 -well plates at a density of $1 \times 10^{5}$ cells/well and transfected with either the pcDNA3.1/pcDNA3.1-Smac or siRNA/control vectors using Lipofectamine ${ }^{\mathrm{TM}} 2000$. After $48 \mathrm{~h}$, indomethacin was added to a final concentration of $100 \mu \mathrm{M}$ (overexpression group) and $400 \mu \mathrm{M}$ (RNA interference group). The following day, the cells were trypsinized (Sigma-Aldrich) and incubated with $5 \mu$ propidium iodide (Invitrogen Life Technologies) and $5 \mu \mathrm{l}$ annexin V-fluorescein isothiocyanate (FITC; Invitrogen Life Technologies) for $15 \mathrm{~min}$. Samples were then analyzed for apoptosis using a FACScan flow cytometer (BD Biosciences, Franklin Lakes, NJ, USA).

Western blotting. Following indomethacin treatment, the EC109 cells were transferred into precooled lysis buffer [50 mM Tris-Cl (pH 7.5), $150 \mathrm{mM} \mathrm{NaCl}$, 1 mM EDTA (pH 8.0), $1 \%$ Triton X-100 and protease inhibitor cocktail; Roche Molecular Biochemicals, Indianapolis, IN, USA] and incubated for $30 \mathrm{~min}$ on ice. Proteins from different samples (30 $\mu \mathrm{g}$ protein/sample) were separated on $12 \%$ SDS-PAGE gels (Invitrogen Life Technologies) and transferred to polyvinylidene fluoride membranes (EMD Millipore, Billerica, MA, USA) by blotting. Subsequent to treatment with 5\% bovine serum albumin (Shanghai Bioleaf Biotech Co., Ltd, Shanghai, China) at room temperature $\left(25^{\circ} \mathrm{C}\right)$ for $1 \mathrm{~h}$, the membranes were incubated with the primary antibody overnight at $4^{\circ} \mathrm{C}$, incubated with horseradish peroxidase-labeled goat anti-rabbit immunoglobulin $\mathrm{G}$ antibody (1:5,000, sc-45101; Santa Cruz Biotechnology, Inc., Dallas, TX, USA) for $1 \mathrm{~h}$ at $25^{\circ} \mathrm{C}$, and developed using electrochemiluminescence detection (ChemiDoc MP System; Bio-Rad Laboratories, Inc.). For the western blot analysis, the following primary antibodies were used: Rabbit monoclonal anti-Smac (1:1,000; 1012-1; Epitomics, Burlingame, CA, USA), rabbit polyclonal anti-Tubulin (1:1,000; 10068-1-AP; ProteinTech Group, Inc., Chicago, IL, USA), rabbit polyclonal anti-GAPDH (1:5,000; 10494-1-AP; ProteinTech Group, Inc.), rabbit monoclonal anti-cytochrome $c$ oxidase subunit IV (COX IV; 1:1,000; 4850; Cell Signaling Technology, Inc., Danvers, MA, USA), rabbit polyclonal anti-caspase-3 (1:1,000; ab2302; Abcam, Cambridge, MA, USA) and rabbit monoclonal anti-pro-caspase-3 (1:1,000; ab32499; Abcam). Tubulin, COX IV and GAPDH were used as loading controls western blot analysis of cytosolic, mitochondria and total protein levels, respectively.

\section{Results}

Indomethacin reduces the viability of the EC109 cells. In order to examine the effect of indomethacin on the EC109 cells, an MTT assay was used initially to investigate the viability of EC109 cells treated with a range of concentrations of indomethacin $(0,50,100,200,400$ and $800 \mu \mathrm{M})$ for 24,48 and $72 \mathrm{~h}$. Indomethacin treatment resulted in a gradual reduction of the viability of the EC109 cells as the exposure duration and drug concentration increased, which indicated that the inhibitory effect of indomethacin on the EC109 cell survival was dose- and time-dependent (Fig. 1). No significant change was observed in the viability of the EC109 cells following indomethacin treatment, for $24 \mathrm{~h}$ while prolonged exposure of the drug for $72 \mathrm{~h}$ resulted in significant cell death. Treatment with indomethacin for $48 \mathrm{~h}$ resulted in a range of EC109 cell viabilities at different concentrations, between $73.58 \%(50 \mu \mathrm{M})$ and $6.57 \%(800 \mu \mathrm{M})$, with a linear correlation between the drug concentration and cell viability (Fig. 1).

Indomethacin treatment releases Smac from mitochondria into the cytosol and activated caspase-3. The EC109 cells were treated with $200 \mu \mathrm{M}$ indomethacin for 0,24 or $48 \mathrm{~h}$ and the expression levels of Smac in the mitochondria and cytosol were analyzed by western blotting. In the absence of indomethacin, Smac was localized to the mitochondria, however, following indomethacin stimulation, Smac was released into the cytosol. The increase in cytosolic levels 


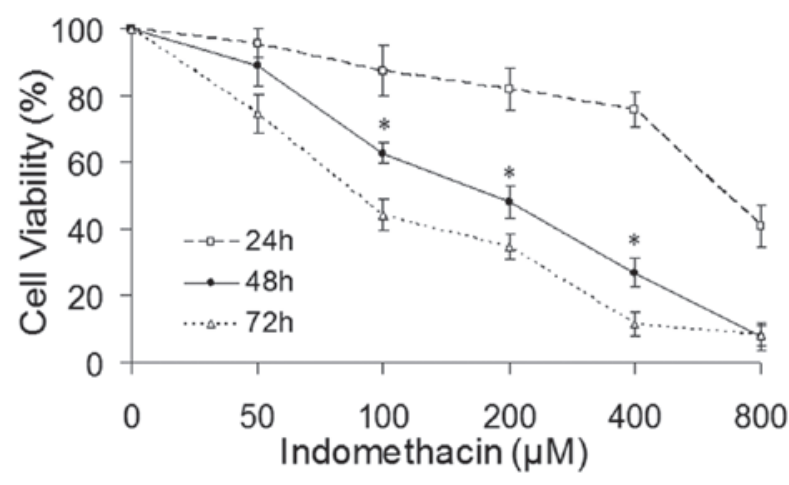

Figure 1. Indomethacin reduces the viability of EC109 cells. The EC109 cells were treated with indomethacin at various concentrations for 24,48 and $72 \mathrm{~h}$, and cell viability was determined using an MTT assay. Data are presented as the mean \pm standard deviation. ${ }^{*} \mathrm{P}<0.05$.
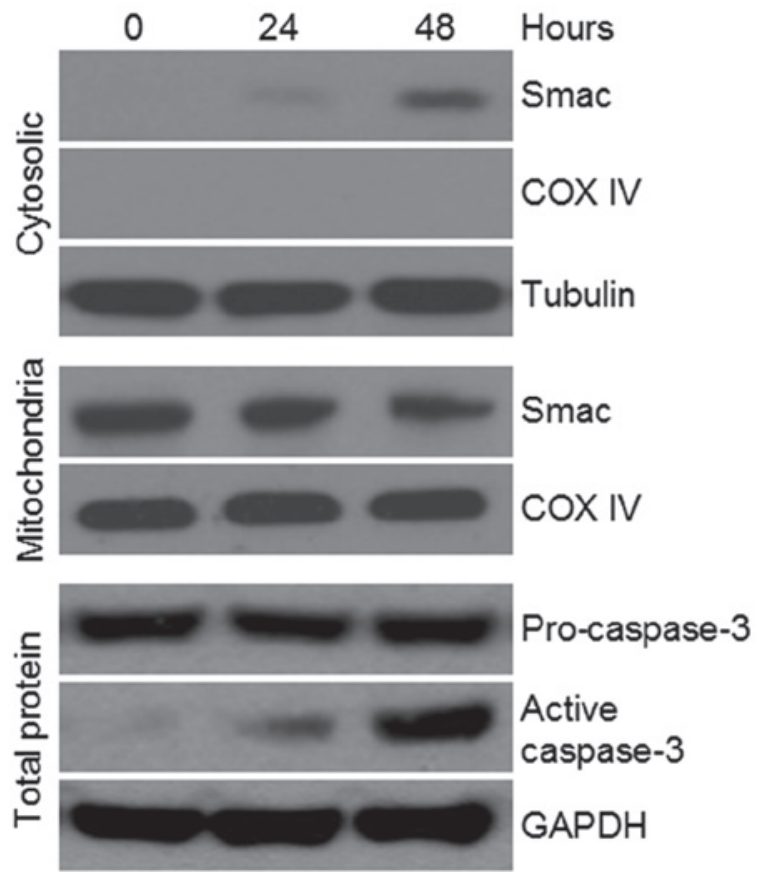

Figure 2. Smac is released from the mitochondria into the cytosol and caspase-3 is activated following treatment with indomethacin. The expression levels of Smac in the mitochondria and cytosol, and the expression of caspase- 3 in the total protein, were examined by western blot analysis following treatment with $200 \mu \mathrm{M}$ indomethacin for 24 or $48 \mathrm{~h}$. COX IV, tubulin and GAPDH were used as loading controls. COX IV, cytochrome $c$ oxidase subunit IV.

of Smac correlated with the activation of caspase-3 during treatment of EC109 cells with indomethacin (Fig. 2). In addition, the release of Smac and the activation of caspase- 3 were prominent following treatment of indomethacin for $48 \mathrm{~h}$. Therefore, a treatment duration of $48 \mathrm{~h}$ was selected for the subsequent experiments.

Smac knockdown inhibits indomethacin-induced apoptosis. To further detect the function of Smac in the EC109 cells treated with indomethacin, siRNA of Smac or its control segment was transfected into the EC109 cells for $48 \mathrm{~h}$. Western blotting confirmed that the expression of Smac in the Smac-knockdown cells was reduced compared with the

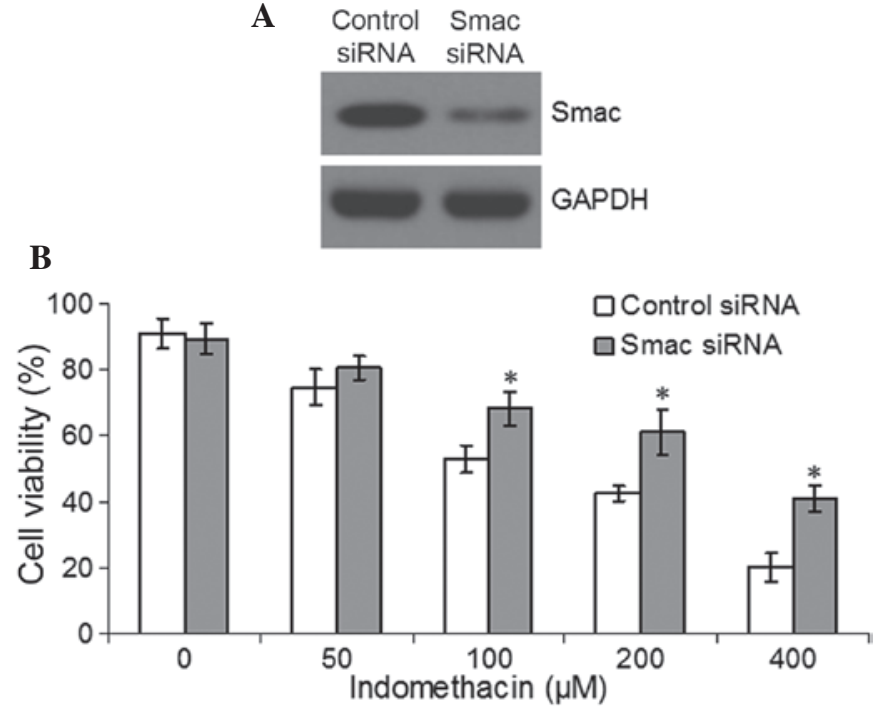

Figure 3. Knockdown of Smac inhibits the reduction of cell viability by indomethacin. (A) Smac was downregulated in the EC109 cells. Protein expression was evaluated by western blot analysis in theEC109 cells following transfection with Smac or control siRNA for $48 \mathrm{~h}$. (B) Cell viability was detected using an MTT assay following treatment of the Smac-downregulated EC109 cells with different concentrations of indomethacin for $48 \mathrm{~h}$. Values are presented as the mean \pm standard deviation $\left({ }^{*} \mathrm{P}<0.05\right.$, vs. contol). Smac, second mitochondria-derived activator of capsase; siRNA, short interference RNA.

control cells (Fig. 3A). The Smac-knockdown EC109 cells and control cells were then treated with different concentrations of indomethacin for $48 \mathrm{~h}$ and the cell viability was assessed by MTT assay. The results identified that the viability of the Smac-knockdown cells was significantly higher compared with the control cells following treatment with 100,200 or $400 \mu \mathrm{M}$ indomethacin ( $\mathrm{P}<0.05$, Fig. 3B).

Following treatment with $400 \mu \mathrm{M}$ indomethacin for $48 \mathrm{~h}$, the Smac-knockdown and control cells were stained with propidium iodide and annexin V-FITC to assess the induction of apoptosis by flow cytometry. In the indomethacin-treated cultures, the number of apoptotic EC109 cells in the Smac-knockdown group was significantly lower compared with the control group ( $\mathrm{P}<0.05$, Fig. $4 \mathrm{~A}$ and $\mathrm{B})$. Furthermore, western blotting demonstrated that the expression of Smac in the cytosol and the activity of caspase-3 were reduced in the Smac-knockdown cells treated with indomethacin, which indicated that knockdown of Smac inhibited the activation of caspase-3, resulting in a reduction in indomethacin-induced apoptosis (Fig. 4C).

Overexpression of Smac enhances indomethacin-induced apoptosis. The EC109 cells were transfected with either pcDNA3.1 or pcDNA3.1-Smac for $48 \mathrm{~h}$ and western blotting confirmed that the overexpression of Smac was successful (Fig. 5A). Tthe cell viability was detected by MTT following treatment with different concentrations of indomethacin. Overexpression of Smac was found to reduce the viability of EC109 following treatment with 50, 100, 200 or $400 \mu \mathrm{M}$ indomethacin $(\mathrm{P}<0.05$, Fig. 5B). Furthermore, flow cytometric analysis indicated that the apoptotic rates of the Smac-overexpressed EC109 cells were significantly higher compared with the control group following treatment with 
A
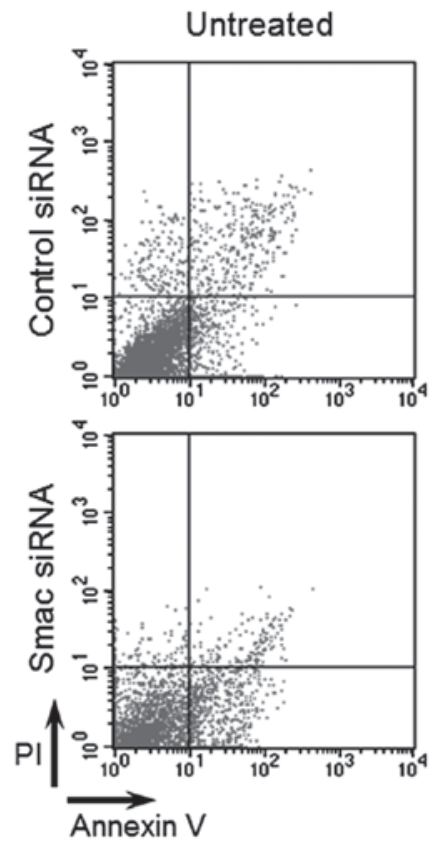

B

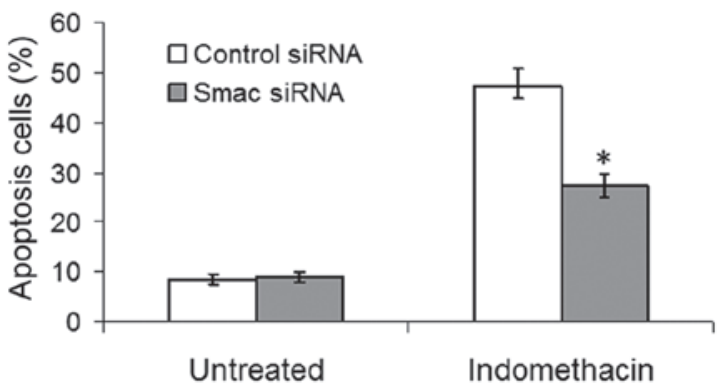

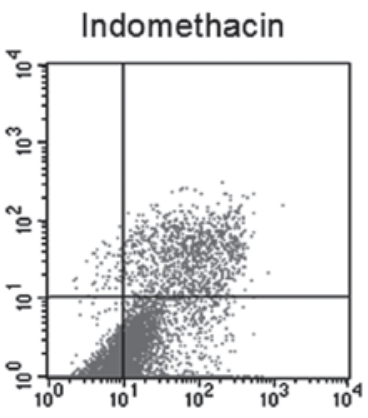
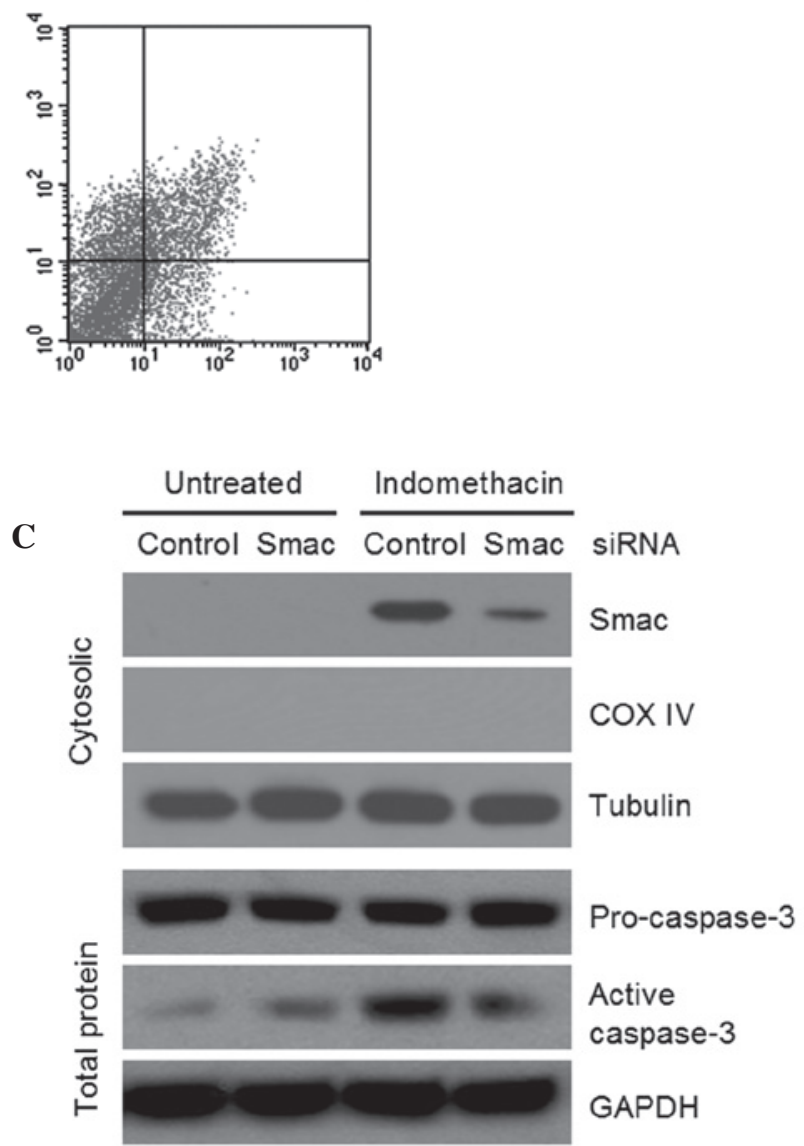

Figure 4. Smac-knockdown inhibits indomethacin-induced apoptosis. (A) EC109 cells were either untreated or exposed for $48 \mathrm{~h}$ to $400 \mu \mathrm{M}$ indomethacin following transfection with Smac or control siRNA for $48 \mathrm{~h}$. Annexin V/PI staining was used for the detection of apoptosis. (B) Apoptotic rates are presented as the mean \pm standard deviation ("P $<0.05$, vs. control). (C) Expression levels of Smac in the cytosol and caspase-3 were detected by western blot analysis. Smac, second mitochondria-derived activator of capsase; COX IV, cytochrome $c$ oxidase subunit IV; PI, propidium iodide; siRNA, short interference RNA.

A

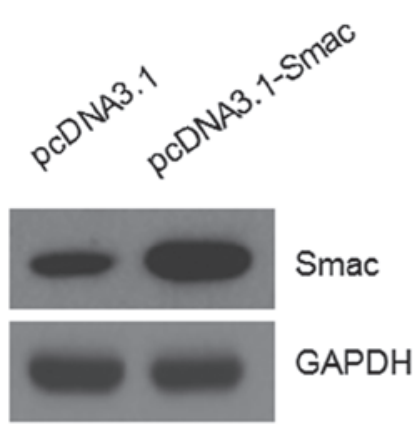

B

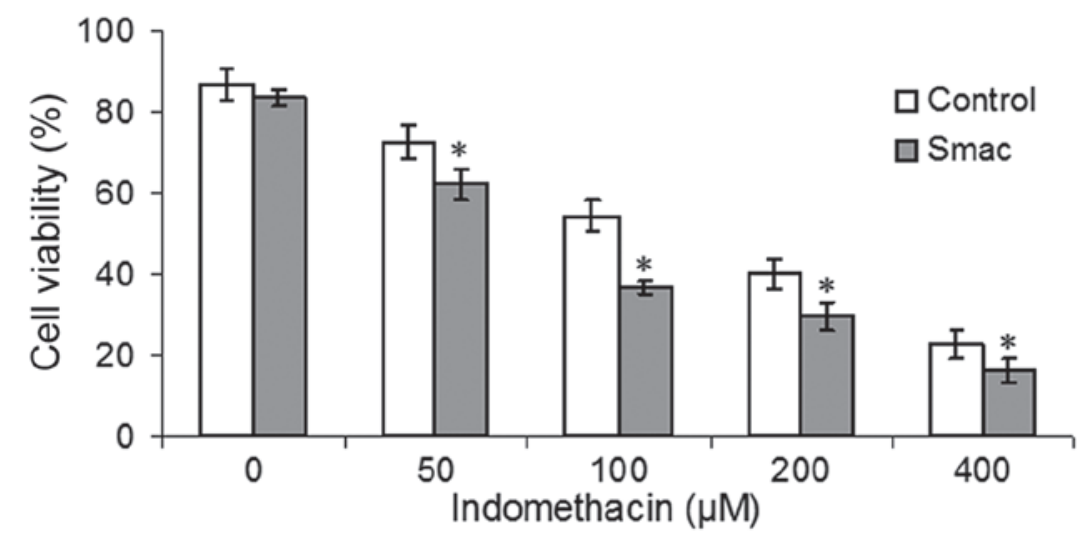

Figure 5. Overexpression of Smac promoted the reduction of cell viability by indomethacin. (A) Smac was overexpressed in the EC109 cells. Protein expression was evaluated by western blotting in the EC109 cells following transfection with the pcDNA3.1-Smac or pcDNA3.1 for $48 \mathrm{~h}$. (B) Cell viability was detected by MTT assay following treatment of the Smac overexpressed EC109 cells with different concentrations of indomethacin for $48 \mathrm{~h}$. ( $\mathrm{P}<0.05$, vs. control). Smac, second mitochondria-derived activator of capsase. 
$\mathbf{A}$
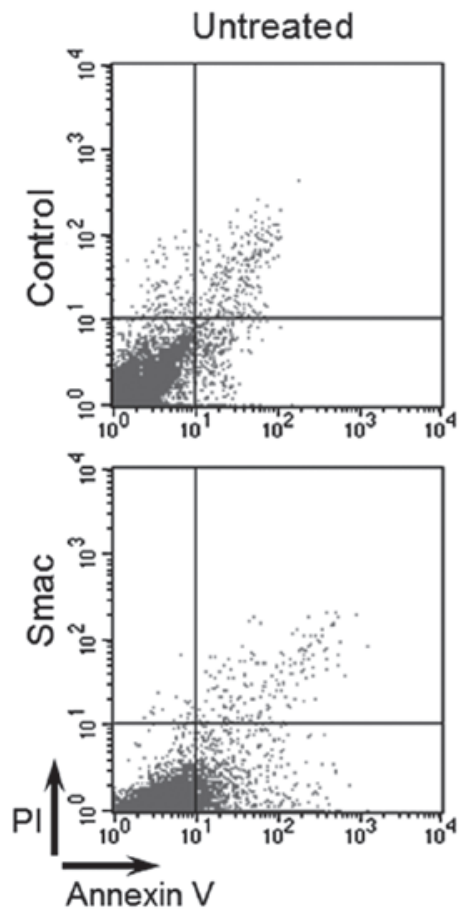

B

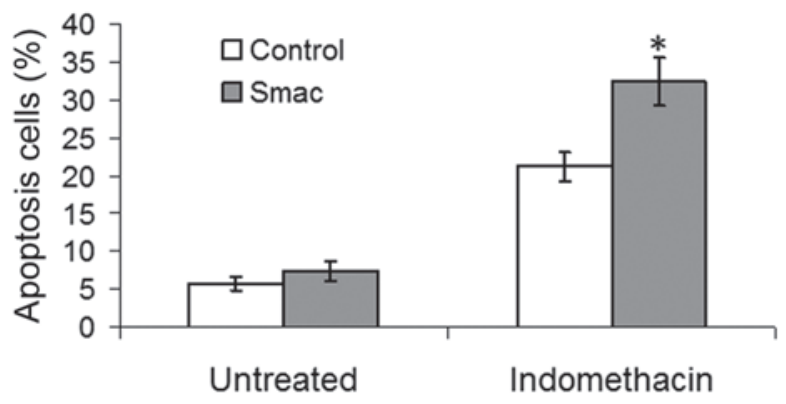

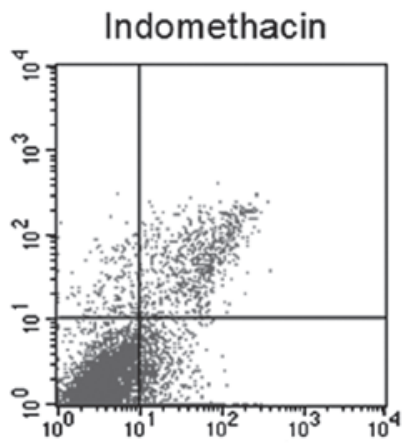

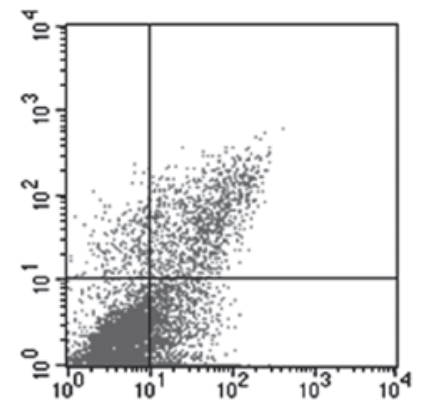

C $\quad \frac{\text { Untreated }}{\text { Control Smac }} \frac{\text { Indomethacin }}{\text { Control Smac }}$
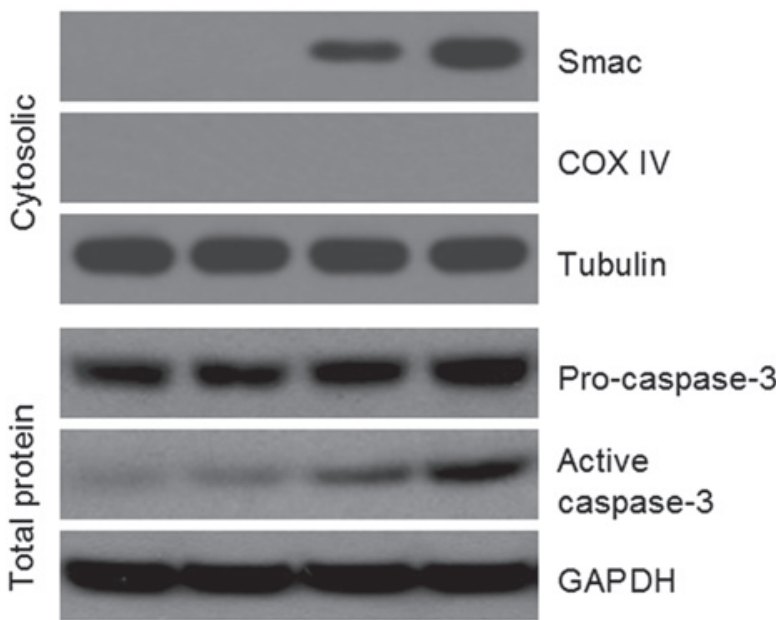

Figure 6. Overexpression of Smac enhances indomethacin-induced apoptosis. (A) EC109 cells were either untreated or were treated for 48 h with $100 \mu \mathrm{M}$ indomethacin following transfection with either pcDNA3.1-Smac or pcDNA3.1 for $48 \mathrm{~h}$. Annexin V/PI staining was then used to detect the rates of apoptosis. (B) Apoptotic rates are presented as the mean \pm standard deviation $(\mathrm{P}<0.05$, vs. control). (C) Expression levels of Smac in the cytosol and caspase-3 were detected by western blot analysis. Smac, second mitochondria-derived activator of capsase; COX IV, cytochrome $c$ oxidase subunit IV; PI, propidium iodide.

$100 \mu \mathrm{M}$ indomethacin $(\mathrm{P}<0.05$, Fig. 6A and B). Finally, western blotting demonstrated that the increased apoptotic rate in the Smac-overexpressing EC109 cells was due to increased levels of cytosolic Smac and caspase-3 activation (Fig. 6C).

\section{Discussion}

NSAIDs are a group of drugs with antipyretic, analgesic, anti-inflammatory and anti-rheumatic properties (15). In addition, previous epidemiological surveys and preliminary clinical studies have indicated that the long-term use of NSAIDs may reduce the risk of colon, stomach, breast, prostate and lung cancer and other types of malignant tumor (16-20). Several studies have demonstrated that NSAIDs may inhibit tumor growth by inhibiting the expression and activity of cyclooxygenase (COX), inducing apoptosis and suppressing angiogenesis $(21,22)$. Kohli et al (9) reported that the NSAID-induced apoptosis in colon cancer cells was dependent on the pro-apoptotic factor, Smac, as knockout or RNA interference of the Smac gene in colon cancer cells significantly reduced the apoptosis induced by NSAIDs. Increasing evidence suggests that the use of NSAIDs also significantly reduces the risk of esophageal cancer, although the mechanism by which NSAIDs inhibit esophageal cancer growth remain to be elucidated $(23,24)$. 
Indomethacin is a commonly used NSAID. It has been observed to induce the apoptosis of lung, head and neck cancer cells $(25,26)$. In the present study, different concentrations of indomethacin were used to treat the EC109 cells. The cell viability and cell growth were significantly inhibited by indomethacin in a dose- and time-dependent manner. Subsequently, western blot analysis revealed that Smac was released into the cytosol and caspase-3 was activated in the EC109 cells treated with indomethacin. Thus, it was hypothesized that indomethacin induced apoptosis in the EC109 cells by activating the Smac-dependent apoptotic pathway. A previous study demonstrated that the release of Smac and cytochrome $c$ occurred during sulindac-induced apoptosis (10). Our previous study described a similar function of Smac in cisplatin-induced apoptosis, in which Smac led to the activation of caspase-3 and -9 in lung cancercells (27).

Smac is an important protein in the mitochondrial apoptotic pathway. Previous studies have revealed a reduction or loss in the expression of Smac in various tumor tissues compared with their normal tissue counterparts, suggesting that Smac functions as a tumor suppressor gene and its abnormally low level of expression is associated with tumorigenesis $(1,3,4)$. In addition, Smac also inhibits tumor growth by promoting apoptosis induced by the tumor necrosis factor-related apoptosis-inducing ligand, enhancing antitumor immune response, inhibiting the cell cycle and sensitizing tumor cells to radiotherapy or chemotherapy $(28,29)$. Reduced expression levels of Smac have been observed in esophageal tumor cell lines and in tumor specimens from patients with esophageal cancer (30). A lower levels of Smac expression has been associated with a reduced sensitivity to chemotherapy in the treatment of esophageal cancer (30). It has also been reported that the overexpression of Smac sensitizes esophageal cancer cells to cisplatin chemotherapy (31).

In the present study, the expression of Smac was increased and decreased in order to further investigate the role of Smac in the indomethacin-induced apoptosis of EC109 cells. The results revealed that knockdown of Smac inhibited the indomethacin-induced apoptosis in the EC109 cells, which were transfected with Smac siRNA. Western blot analysis demonstrated that indomethacin treatment of Smac-knockdown EC109 cells reduced the cytosolic expression of Smac and the activation of caspase-3. These results suggested that the translocation of Smac from the mitochondria to the cytosol was important in promoting the activation of caspase- 3 and the indomethacin-induced apoptosis. To further investigate the effects of indomethacin-induced apoptosis, the apoptotic rates and activation of caspase-3 were measured following overexpression of Smac in the EC109 cells. The results were consistent with those of the Smac-knockdown experiments, indicating that indomethacin-induced apoptosis is dependent on and regulated by Smac and caspase-3. These observations regarding the role of Smac in indomethacin-induced apoptosis in EC109 cells provides a novel treatment strategy for esophageal cancer.

At present, Smac mimetics, which are composed of the last four-eight $\mathrm{N}$-terminal residues of Smac, have been successfully applied in cancer treatment in the laboratory, and are being assessed in early clinical studies $(32,33)$. Smac mimetics have also been combined with several chemotherapeutic drugs to enhance the efficacy of chemotherapy and to overcome drug resistance (34-36). However, at present, few studies have been performed on the combined use of Smac peptides and NSAIDs. NSAIDs are inexpensive and relatively non-toxic compared with conventional chemotherapeutic drugs (37). Whether the combination of NSAIDs and Smac peptides is more effective compared with either alone in inducing apoptosis in esophageal cancer cells, with or without low dose chemotherapeutic agents, remains to be elucidated and is of interest.

\section{Acknowledgements}

The present study was supported by the Shannxi Province Science and Technology Fund (grant no. 2010K01-133) and the Chinese National Natural Science Foundation (grant nos. 81272418 and 81402506).

\section{References}

1. Du C, Fang M, Li Y, Li L and Wang X: Smac, a mitochondrial protein that promotes cytochrome c-dependent caspase activation by eliminating IAP inhibition. Cell 102: 33-42, 2000.

2. Verhagen AM, Ekert PG, Pakusch M, et al: Identification of DIABLO, a mammalian protein that promotes apoptosis by binding to and antagonizing IAP proteins. Cell 102: 43-53, 2000.

3. Qin S, Yang C, Li S, Xu C, Zhao Y and Ren H: Smac: Its role in apoptosis induction and use in lung cancer diagnosis and treatment. Cancer Lett 318: 9-13, 2012.

4. Martinez-Ruiz G, Maldonado V, Ceballos-Cancino G, Grajeda JP and Melendez-Zajgla J: Role of Smac/DIABLO in cancer progression. J Exp Clin Cancer Res 27: 48, 2008.

5. Srinivasula SM, Hegde R, Saleh A, et al: A conserved XIAP-interaction motif in caspase-9 and Smac/DIABLO regulates caspase activity and apoptosis. Nature 410: 112-116, 2001.

6. Liu WW, Liu Y, Liang S, Wu JH, Wang ZC and Gong SL: Hypoxia- and radiation-induced overexpression of Smac by an adenoviral vector and its effects on cell cycle and apoptosis in MDA-MB-231 human breast cancer cells. Exp Ther Med 6: 1560-1564, 2013.

7. Liu BH, Chen L, Li SR, Wang ZX and Cheng WG: Smac/DIABLO regulates the apoptosis of hypertrophic scar fibroblasts. Int J Mol Med 32: 615-622, 2013.

8. Thun MJ, Jacobs EJ and Patrono C: The role of aspirin in cancer prevention. Nat Rev Clin Oncol 9: 259-267, 2012.

9. Kohli M, Yu J, Seaman C, et al: SMAC/Diablo-dependent apoptosis induced by nonsteroidal anti inflammatory drugs (NSAIDs) in colon cancer cells. Proc Natl Acad Sci USA 101: 16897-16902, 2004.

10. Bank A, Wang P, Du C, Yu J and Zhang L: SMAC mimetics sensitize nonsteroidal anti-inflammatory drug-induced apoptosis by promoting caspase-3-mediated cytochrome c release. Cancer Res 68: 276-284, 2008.

11. Jemal A, Bray F, Center MM, Ferlay J, Ward E and Forman D: Global cancer statistics. CA Cancer J Clin 61: 69-90, 2011.

12. Bardou M, Barkun AN, Ghosn J, Hudson M and Rahme E: Effect of chronic intake of NSAIDs and cyclooxygenase 2-selective inhibitors on esophageal cancer incidence. Clin Gastroenterol Hepatol 2: 880-887, 2004.

13. Corley DA, Kerlikowske K, Verma R and Buffler P: Protective association of aspirin/NSAIDs and esophageal cancer: a systematic review and meta-analysis. Gastroenterology 124: 47-56, 2003.

14. Qin SD, Ren H, Li XJ, et al: Construction and expression of eukaryotic expression plasmid pcDNA3.1-smac. Xi Bao Yu Fen Zi Mian Yi Xue Za Zhi 27: 146-149, 2011 (In Chinese).

15. Gurpinar E, Grizzle WE and Piazza GA: NSAIDs inhibit tumorigenesis, but how? Clin Cancer Res 20: 1104-1113, 2014.

16. Antonakopoulos N and Karamanolis DG: The role of NSAIDS in colon cancer prevention. Hepatogastroenterology 54: 1694-1700, 2007.

17. Zhang YJ,DaiQ,Wu SM,et al: Susceptibility for NSAIDs-induced apoptosis correlates to p53 gene status in gastric cancer cells. Cancer Invest 26: 868-877, 2008. 
18. Brasky TM, Bonner MR, Moysich KB, et al: Non-steroidal anti-inflammatory drugs (NSAIDs) and breast cancer risk: differences by molecular subtype. Cancer Causes Control 22: 965-975, 2011.

19. Cheng I, Liu X, Plummer SJ, Krumroy LM, Casey G and Witte JS: COX2 genetic variation, NSAIDs, and advanced prostate cancer risk. Br J Cancer 97: 557-561, 2007.

20. Skriver MV, Nørgaard M, Poulsen AH, et al: Use of nonaspirin NSAIDs and risk of lung cancer. Int J Cancer 117: 873-876, 2005.

21. Jana NR: NSAIDs and apoptosis. Cell Mol Life Sci 65 1295-1301, 2008.

22. Tarnawski AS and Jones MK: Inhibition of angiogenesis by NSAIDs: molecular mechanisms and clinical implications. J Mo Med (Berl) 81: 627-636, 2003.

23. Sun L and Yu S: Meta-analysis: non-steroidal anti-inflammatory drug use and the risk of esophageal squamous cell carcinoma. Dis Esophagus 24: 544-549, 2011.

24. Liao LM, Vaughan TL, Corley DA, et al: Nonsteroidal anti-inflammatory drug use reduces risk of adenocarcinomas of the esophagus and esophagogastric junction in a pooled analysis. Gastroenterology 142: 442-485, 2012.

25. Cai JB, Zhang CX, Luo JW and Wang D: A study of ${ }^{131}$ iodine labeling of indomethacin, its in vivo biological distribution in Lewis-bearing lung cancer, and its induction of apoptosis in lung cancer. Saudi Med J 32: 15-22, 2011.

26. Pelzmann M, Thurnher D, Gedlicka C, Martinek H and Knerer B: Nimesulide and indomethacin induce apoptosis in head and neck cancer cells. J Oral Pathol Med 33: 607-613, 2004.

27. Qin S, Yang C, Wang X, et al: Overexpression of Smac promotes Cisplatin-induced apoptosis by activating caspase-3 and caspase-9 in lung cancer A549 cells. Cancer Biother Radiopharm 28: 177-182, 2013.
28. Zhang XD, Zhang XY, Gray CP, Nguyen T and Hersey P: Tumor necrosis factor-related apoptosis-inducing ligand-induced apoptosis of human melanoma is regulated by Smac/DIABLO release from mitochondria. Cancer Res 61: 7339-7348, 2001.

29. Greer RM, Peyton M, Larsen JE, et al: SMAC mimetic (JP1201) sensitizes non-small cell lung cancers to multiple chemotherapy agents in an IAP-dependent but TNF- $\alpha$-independent manner. Cancer Res 71: 7640-7648, 2011

30. Xu Y, Zhou L, Huang J, et al: Role of Smac in determining the chemotherapeutic response of esophageal squamous cell carcinoma. Clin Cancer Res 17: 5412-5422, 2011.

31. Du N, Yang B, Hu L, et al: Overexpression of Smac gene erhanced chemotherapeutic sensitivity of esophageal cancer cell line Eca109 to cisplatin. Xi Bao Yu Fen Mian Yi Xue Za Zhi 28: 344-346, 2012 (In Chinese).

32. Fulda S: Molecular pathways: targeting death receptors and smac mimetics. Clin Cancer Res 20: 3915-3920, 2014.

33. Bai L, Smith DC and Wang S: Small-molecule SMAC mimetics as new cancer therapeutics. Pharmacol Ther 144: 82-95, 2014.

34. Li L, Thomas RM, Suzuki H, De Brabander JK, Wang X and Harran PG: A small molecule Smac mimic potentiates TRAILand TNFalpha-mediated cell death. Science 305: 1471-1474, 2004.

35. Petersen SL, Wang L, Yalcin-Chin A, et al: Autocrine TNFalpha signaling renders human cancer cells susceptible to smac-mimetic-induced apoptosis. Cancer Cell 12: 445-456, 2007.

36. Mao HL, Pang Y, Zhang X, et al: Smac peptide potentiates TRAIL- or paclitaxel-mediated ovarian cancer cell death in vitro and in vivo. Oncol Rep 29: 515-522, 2013.

37. Bahadur S, Keshri L and Pathak K: Adverse drug reactions and safety considerations of NSAIDs: clinical analysis. Curr Drug Saf 6: 310-7, 2011. 